\title{
International airport impacts to air quality: size and related properties of large increases in ultrafine particle number concentrations
}

N. Hudda ${ }^{1}$ and S.A. Fruin ${ }^{1 *} \dagger$

${ }^{1}$ Keck School of Medicine, Environmental Health Division, University of Southern California, Los Angeles, CA 90033, United States

Corresponding Author

*Telephone: 323-442-2870. Fax: 323-442-3272. E-mail: fruin@ usc.edu.

Present Address

$\dagger$ †. A. Fruin: Department of Preventive Medicine, Environmental Health Sciences, University of Southern California, 2001 North Soto Street, Los Angeles, CA 90089-9013, United States

Number of Pages: 10

Number of Figures: 8

Number of Tables: 2 


\section{COMPARISON OF VARIOUS INSTRUMENTS}

\section{COMPARISON OF SIZES REPORTED BY SMPS AND DISCMINI}

Data from stationary monitoring, collected away from major roadways to allow stable PN concentrations, were analyzed for agreement between the size statistics reported by the Nanoscan SMPS and the DiSCMini. Figure S1 shows data from stationary monitoring (761 one minute samples). For particles smaller than $40 \mathrm{~nm}$, the DiSCMini underestimated the number average size compared to the mean size reported by TSI Nano SMPS 3681 operating at 1 minute scan mode, and this difference is significantly larger than the manufacturer specified $\pm 30 \%$ accuracy ${ }^{1}$. However, the overall the agreement was within $\pm 30 \%$ and data were highly correlated. The following Table 1 shows the statistics for linear regression for DiSCMini reported number average diameter and size statistics reported by the SMPS.

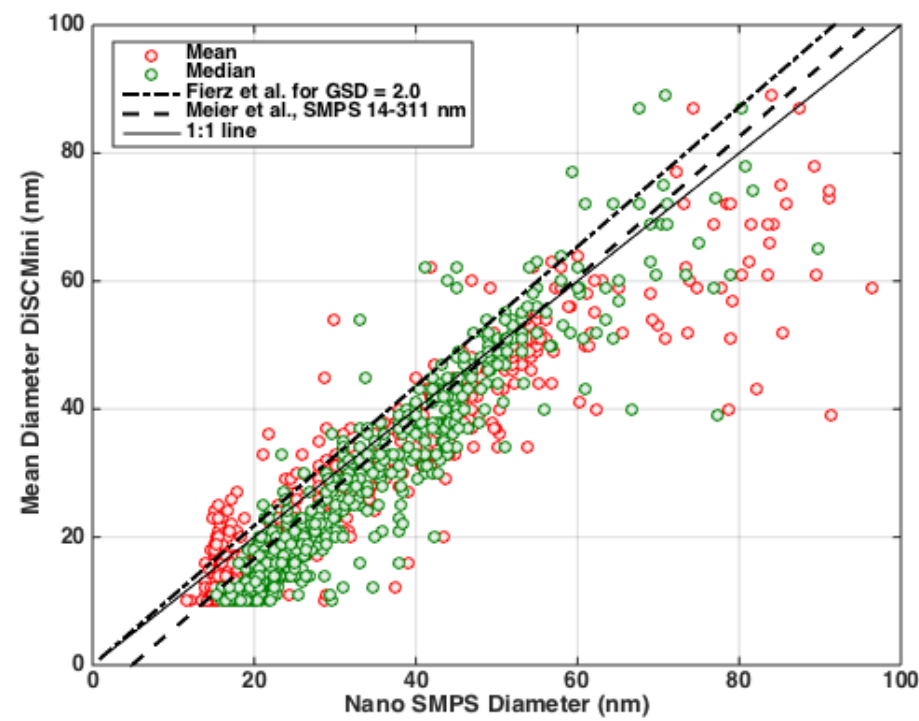

Figure S1: Comparison of average size reported by DiSCMini and size statistics reported by SMPS during stationary monitoring

Table S1: Statistics for robust bi-square linear regression between DiSCMini reported number average diameter and size statistics reported by the SMPS

\begin{tabular}{|c|c|c|c|c|c|c|c|}
\hline $\begin{array}{c}\text { SMPS size } \\
\text { statistic }\end{array}$ & Slope & $\begin{array}{c}95 \% \text { Confidence } \\
\text { Intervals }\end{array}$ & $\begin{array}{c}\mathrm{Y} \\
\text { Intercep } \\
\mathrm{t}(\mathrm{nm})\end{array}$ & $\begin{array}{c}95 \% \text { Confidence } \\
\text { Intervals }(\mathrm{nm})\end{array}$ & SSE & $\mathrm{r}^{2}$ & $\begin{array}{c}\text { RMSE } \\
(\mathrm{nm})\end{array}$ \\
\hline Mean & 0.94 & $(0.92,0.96)$ & -2.17 & $(-2.82,-1.52)$ & $1.326 \mathrm{e} 4$ & 0.94 & 4.33 \\
\hline Geo Mean & 1.01 & $(0.99,1.03)$ & -14.08 & $(-14.97,-13.2)$ & $1.320 \mathrm{e} 4$ & 0.94 & 4.32 \\
\hline Median & 1.18 & $(1.16,1.20)$ & -10.86 & $(-11.54,-10.17)$ & $0.919 \mathrm{e} 4$ & 0.96 & 3.61 \\
\hline
\end{tabular}


Because the DiSCMini bases particle size on ratios of the charged particles collected in two stages, and because charging efficiency is a function of particle size, the agreement between the size statistics reported by DM and SMPS depend on the assumed geometric standard deviation $\left(\sigma_{\mathrm{g}}\right)$ of the size distribution. Fierz et al. ${ }^{1}$ report regression models for miniature DiSC (original prototype of DiSCMini) mean diameter and mean diameter measured using homebuilt SMPS by Umweltund Gesundheitsamt Zurichas (diameter range of $10-320 \mathrm{~nm}$ ) and TSI CPC Model 3775 as:

$-\mathrm{d}\left(\right.$ miniature DiSC,$\left.\sigma_{\mathrm{g}}=1.7\right)=1.26 * \mathrm{~d}(\mathrm{SMPS}) ; \mathrm{R}^{2}=0.99$ (forced intercept zero regression)

$-\mathrm{d}\left(\right.$ miniature DiSC,$\left.\sigma_{\mathrm{g}}=2.0\right)=1.09 * \mathrm{~d}(\mathrm{SMPS}) ; \mathrm{R}^{2}=0.99$ (forced intercept zero regression)

We sorted our samples by $\sigma_{\mathrm{g}}$ and the regression models for two $\sigma_{\mathrm{g}}$ ranges were:

For 1.65<的 $<1.75$ :

$-d($ miniature $\mathrm{DiSC})=0.75^{*}$ geomean $\mathrm{d}(\mathrm{SMPS}) ; \mathrm{R}^{2}=0.84$ for a forced intercept zero regression

$-\mathrm{d}($ miniature $\mathrm{DiSC})=1.20$ * geomean $\mathrm{d}(\mathrm{SMPS})-12.1 ; \mathrm{R}^{2}=0.98$

For $1.95<\sigma_{\mathrm{g}}<2.05$ :

$-\mathrm{d}($ miniature $\mathrm{DiSC})=0.97^{*}$ geomean $\mathrm{d}(\mathrm{SMPS}) ; \mathrm{R}^{2}=0.89$ for a forced intercept zero regression

$-\mathrm{d}($ miniature $\mathrm{DiSC})=1.26$ * geomean $\mathrm{d}(\mathrm{SMPS})-12.3 ; \mathrm{R}^{2}=0.93$

Our results differ from Fierz et al. ${ }^{1}$ but agree with Meier et al. ${ }^{2}$ results for regression between mean DiSCMini diameter and geometric mean diameter measured using Grimm SMPS+ C (Differential Mobility Analyzer model 5540-long UDMA and a CPC model 5.403) were similar to ours.

Meier et al. ${ }^{2}$ results were as follows:

\begin{tabular}{|llllr|}
\hline X & \multicolumn{1}{c}{ Y } & R2 & Slope & Intercept \\
\hline sizeminiDisc & sizesMPS10-1,110 & 0.85 & 1.02 & -9.42 \\
\hline sizeminiDisc & sizesMPS13-311 & 0.86 & 0.91 & 4.87 \\
\hline sizeminiDisc & sizesMPS16-311 & 0.76 & 0.77 & 15.93 \\
\hline
\end{tabular}

Asbach et al. ${ }^{3}$ have also compared the DiSCMini with a TSI FMPS. They also found that the DiSCMini underestimates the particle size for particles smaller than $30 \mathrm{~nm}$. For example, for soot particles, FMPS reported geometric average diameter as $28.2 \pm 0.42 \mathrm{~nm}$ and two DiSCMinis reported number-average diameters as $25.1 \pm 0.40 \mathrm{~nm}$ and $22.9 \pm 0.32 \mathrm{~nm}$. In our data, for NanoSMPS samples with arithmetic mean in the range $33-37 \mathrm{~nm}$, the geometric mean was $27.9 \pm 1.36 \mathrm{~nm}$ and DiSCMini reported number average diameter as $21.3 \pm 2.98 \mathrm{~nm}$. 


\section{COMPARISON OF PN CONCENTRATIONS REPORTED BY CPC AND DISCMINI}

We do not report any PN concentrations measured using DiSCMini in this study but the comparison is useful as a reference for other field studies. Figure S2 (a) shows time series of 1 sec resolution PN concentration data collected using the DiSCMini and a TSI CPC 3007 that has a $d_{50}$ cutoff size of $10 \mathrm{~nm}$. DiscMini overestimates the number concentration relative to a CPC 3007 when particle size decreases. This tended to be during higher number concentrations, as shown in S2 (a) in the latter portions of each hour.

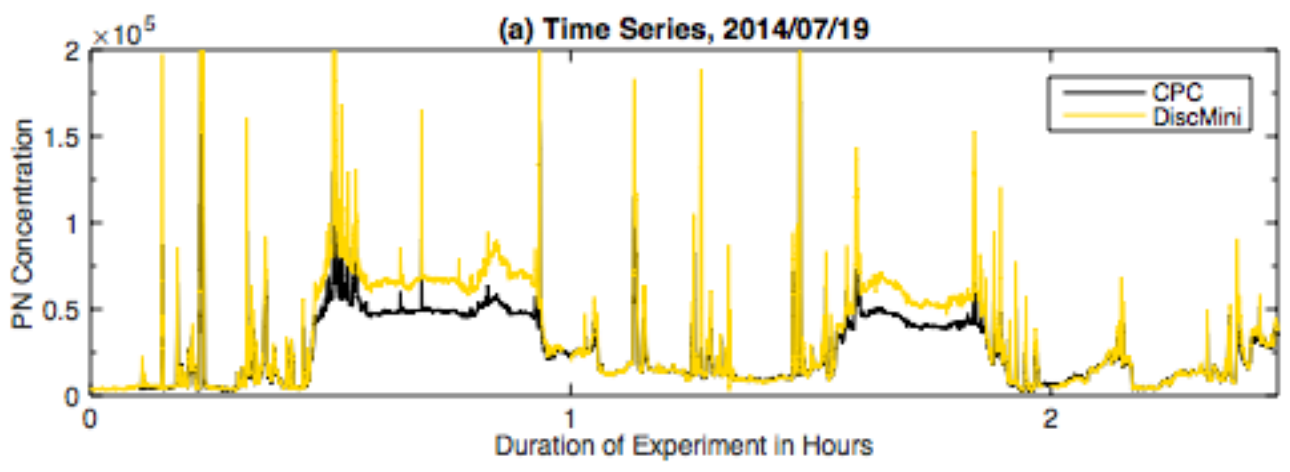

Figure S2 (a): Time series of PN concentration measured simultaneously by CPC and DiSCMini.

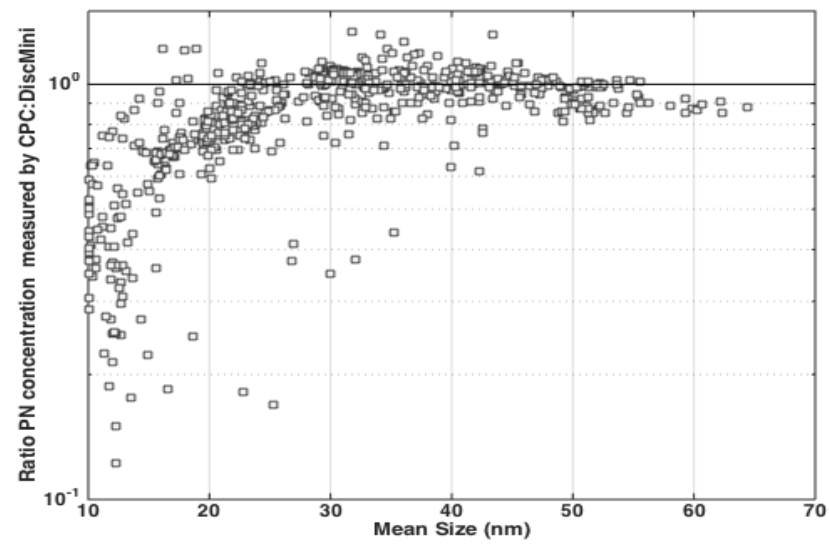

Figure S2 (b): Ratio 1 minute average PN concentration reported by CPC and DiSCMini vs mean size measured using DiSCMini for mobile monitoring on July 19, 2014.

The ratio of one minute average number concentration reported by DiSCmini to that reported by CPC 3007 is shown in Figure S2 (b). The ratio of one minute concentrations was $0.98 \pm 0.11$ when mean size was greater than or equal to $30 \mathrm{~nm}$ and the ratio was $0.70 \pm 0.25$ when mean size was less than $30 \mathrm{~nm}$. Several other studies have reported similar results and that agreement between CPC and DiSCmini reported number concentrations has a size dependence. ${ }^{2,4-5}$ 
Regression models between one minute average PN concentrations transformed to log to the base of 10 are presented below in Figure S2 (c) for data from 2 monitoring runs (July 14 and July 15, 2014). High degree of correlation between CPC and DiSCMini reported concentrations suggests that DiSCMini is a good portable instrument and a possible CPC substitute for studies that require an instrument with a fast response time.
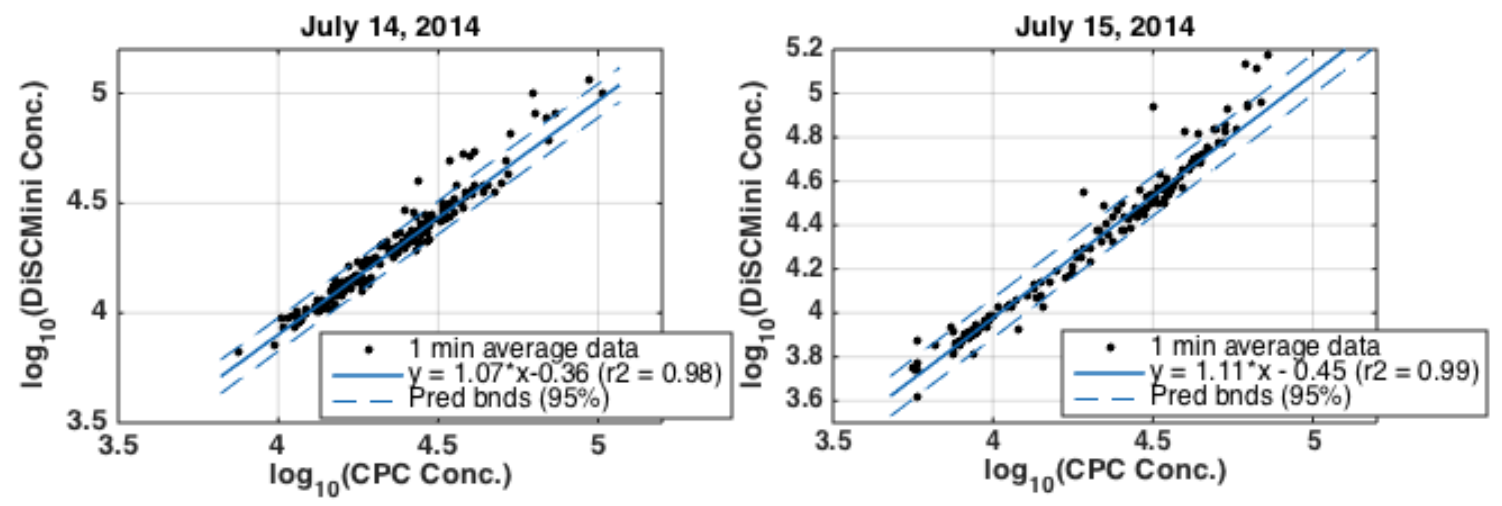

Figure S2 (c): PN concentration reported by DiSCMIni vs. that reported by CPC and liner regression model for 1 minute average mobile motoring data.

DATA PROCESSING
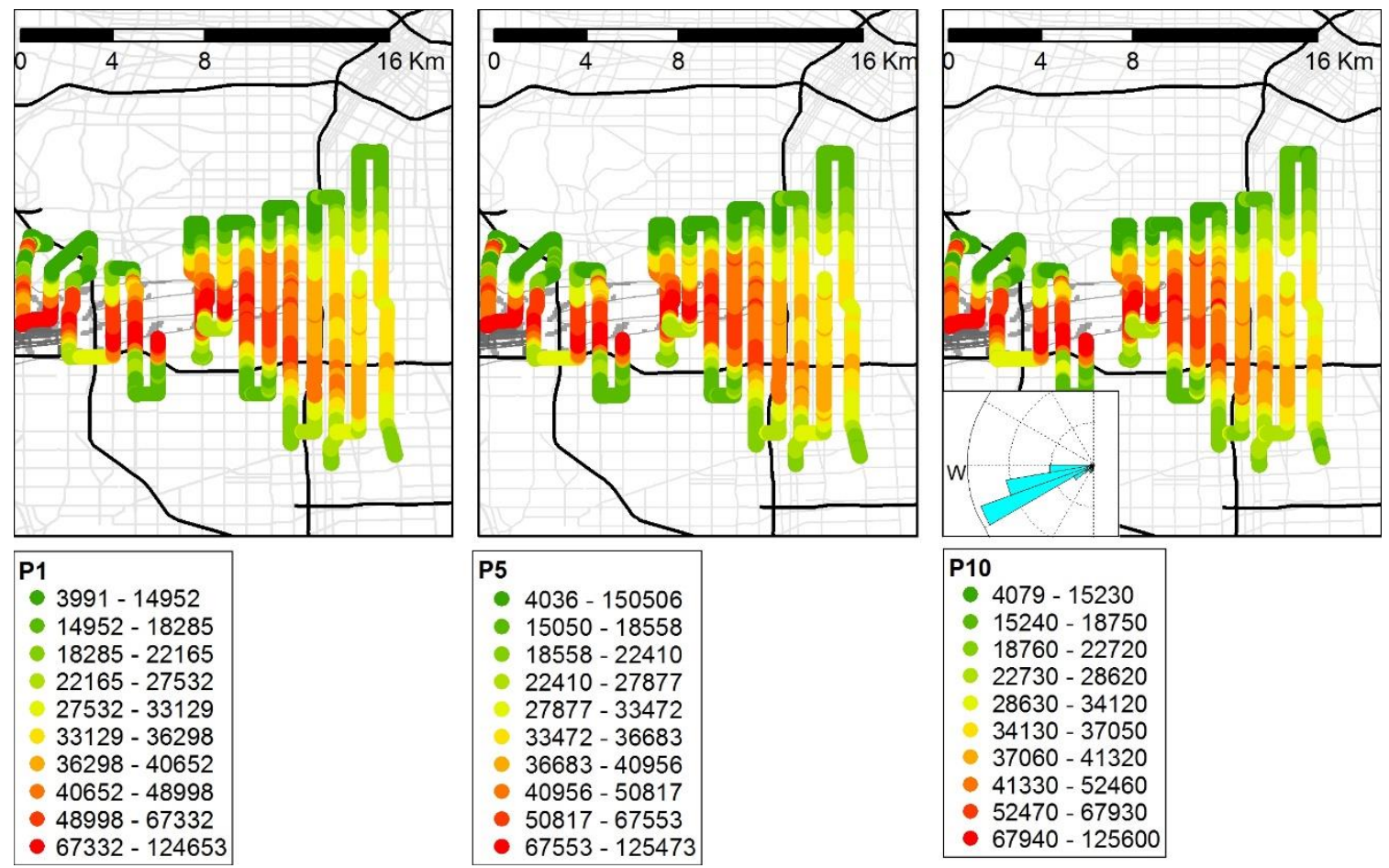

Figure S3: Spatial pattern of elevated PN concentrations during nighttime on Aug 23-24, 2013 discussed in Hudda et al. ${ }^{6}$ and typical of this study. 


\section{DEPOSITION FRACTIONS}

Londahl et al. ${ }^{7}$ measured lung deposition in 9 healthy subjects exposed to curbside aerosol that had $10-30 \%$ hygroscopic fraction in the $10-600 \mathrm{~nm}$ size range. Data from their Figure 5 was interpolated using the linear fit between nearest neighbors to obtain values for deposition fractions by number (DFN) corresponding to the mobility diameters associated with our data. The values are presented in Table S2 and both the Londahl et al. ${ }^{7}$ experimentally measured values and the interpolated values used in this study have been plotted in Figure S3.

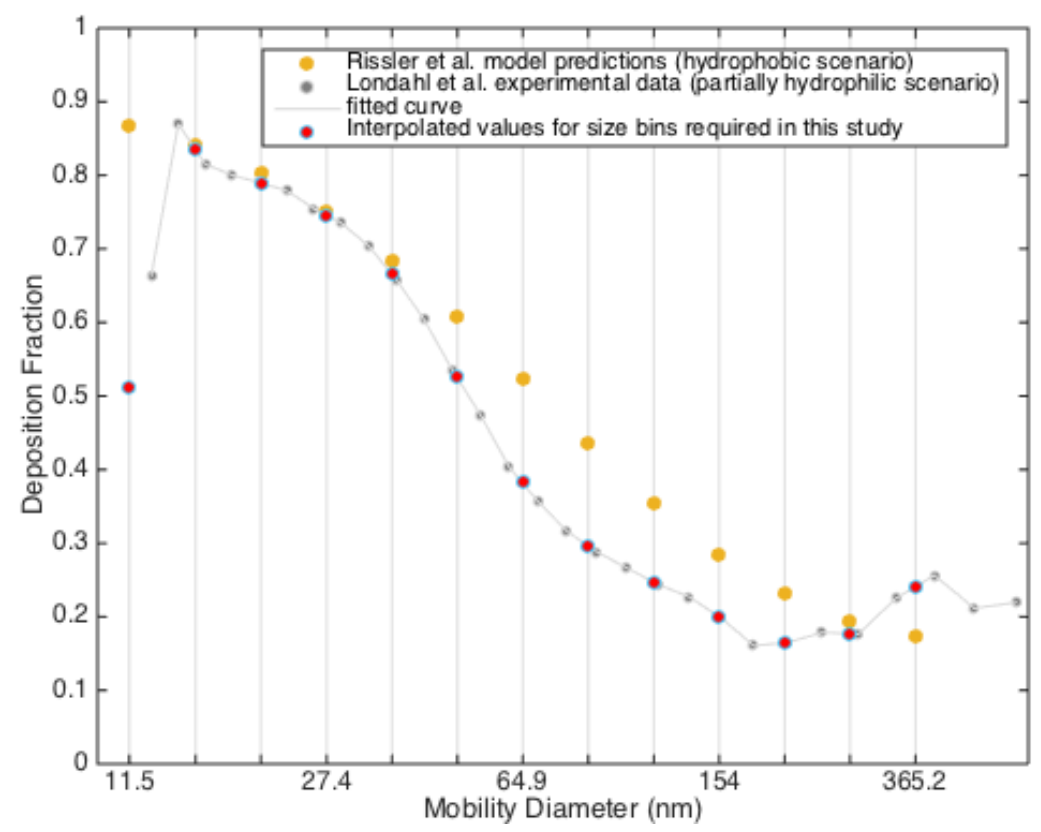

Figure S4: Deposition fraction for number concentration versus particle mobility diameter.

Table S2: Size specific deposition fraction values used to calculate total deposition fraction in this study

\begin{tabular}{|l|r|r|r|r|r|r|r|r|r|r|r|r|r|}
\hline $\begin{array}{l}\text { Mobility } \\
\text { Diameter (nm) }\end{array}$ & 11.5 & 15.4 & 20.5 & 27.4 & 36.5 & 48.7 & 64.9 & 86.6 & 116 & 154 & 205 & 274 & 365 \\
\hline Rissler et al. & 0.87 & 0.84 & 0.80 & 0.75 & 0.69 & 0.61 & 0.52 & 0.44 & 0.35 & 0.29 & 0.23 & 0.19 & 0.17 \\
\hline Löndahl et al. & 0.51 & 0.84 & 0.79 & 0.75 & 0.67 & 0.52 & 0.38 & 0.30 & 0.25 & 0.20 & 0.16 & 0.18 & 0.24 \\
\hline
\end{tabular}

Rissler et al. ${ }^{8}$ parameterized a size-dependent DFN model based on total respiratory tract deposition results in 10 healthy subjects exposed to nearly hydrophobic fresh diesel engine exhaust in 10-500 $\mathrm{nm}$ size range. They reported the model in Equation 7 in their article as:

$$
D F\left(d_{m e}\right)=a_{k}+b_{k} d_{m e}-\frac{1}{c_{k}\left(\frac{C_{c}}{d_{m e}}\right) d^{k}+1}
$$


where $a_{k}$ is $0.924, b_{k}$ is $0.25, c_{k}$ is $0.0658, d_{k}$ is $0.76, d_{m e}$ is the mobility diameter and Cc is the Cunningham slip correction factor. This equation was used to calculate DFN values for the mobility diameters bins of our data. The values are also reported in Table S2.

\section{ADDITIONAL FIGURES RELATED TO RESULTS SECTION}
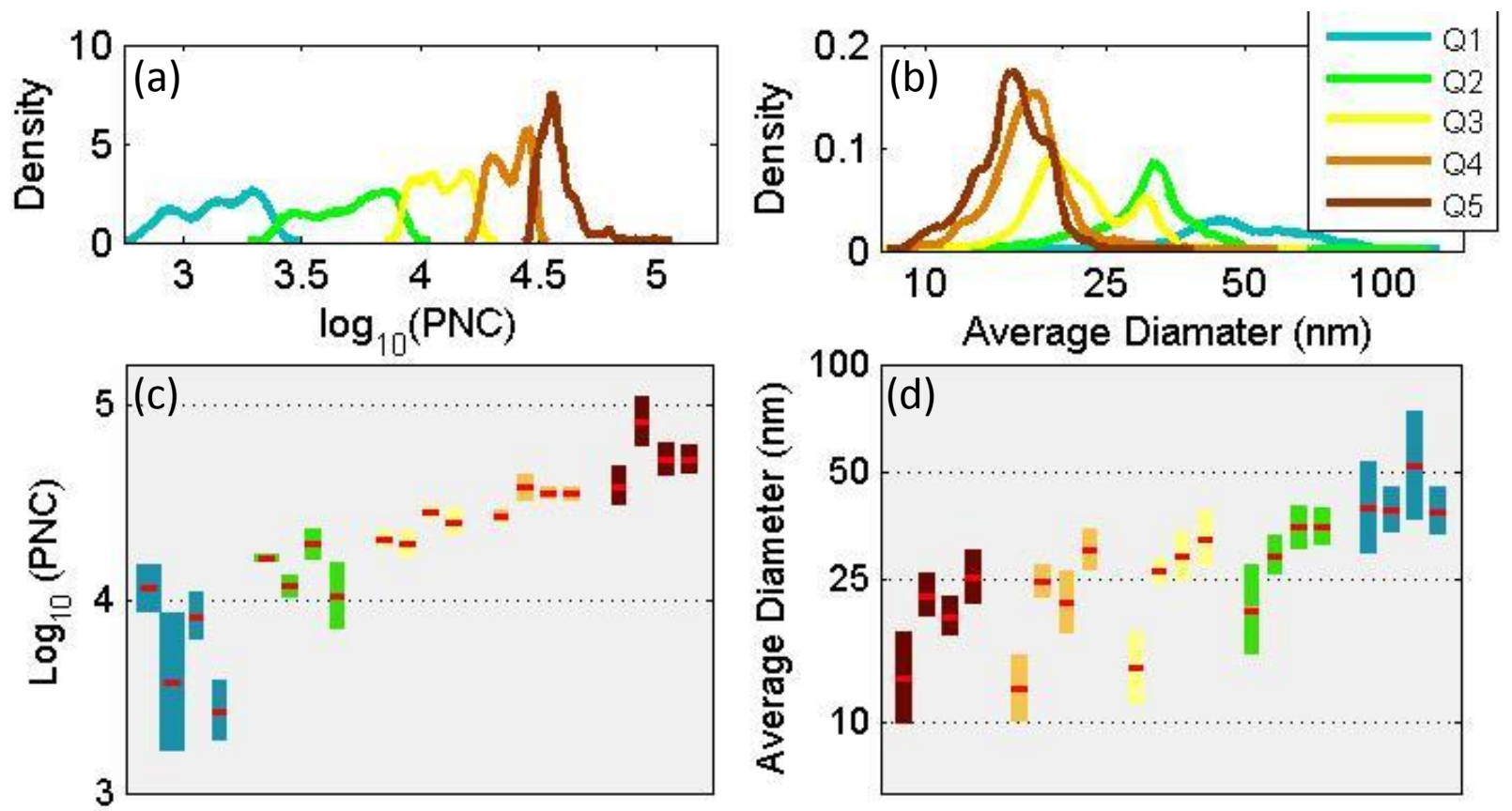

Figure S5 (a)-(b): Density functions for PN concentration and size for data shown in Figure 2 (a) \& (b) split into five categories based on quintiles ( $Q$ being the lowest, i.e., $<20^{\text {th }}$ percentile data and Q5 being the highest, i.e., > 80\% percentile data). (c)-(d): Average and standard deviation of PN concentration and average size and for four monitoring runs (July 14, 16, 18 and 20, 2014, plotted in that order from left to right) categorized quintile-wise based on baseline PN concentration (Q1 to Q5). The red horizontal line in the middle of the bar marks the average concentration and bar length marks the standard deviation on each side.

Stationary measurements were also conducted near the blast fence. This location is only 100-200 $\mathrm{m}$ from the western end from the runway and the closest we could get to the blast fence without being inside the airport complex. By virtue of proximity, we assume that this is the location most impacted by idling and takeoffs in addition to being impacted by landing jet emissions. The following graph for data from this location during 0100 hour when only jet takeoffs and idling was occurring near the west end of the runway is shown in Figure S6. During this hour flights landed on east end of the runway, i.e., there were no overhead arrivals. Although we observed spikes in PN concentrations coinciding with changes in size distributions, the size distribution itself did not differ significantly. A similar observation was also reported by Westerdahl et $\mathrm{al}^{9}$ who studied emission in proximity of LAX. 


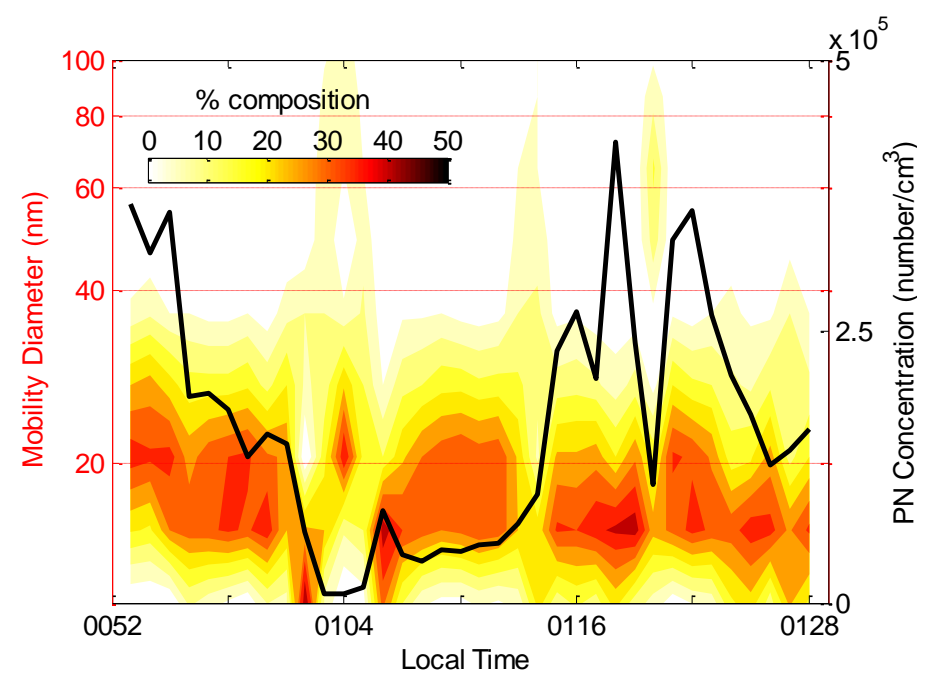

Figure S6: Time series for 1 minute average PN concentration and size distribution (shown as percent of total particles per mobility diameter bin) during 0100 hour, July 20, 2014 measured within 200 m downwind of a runway.

The following figure shows typical examples of non-normalized distributions. Given the large differences in concentration, demonstrated below, between impacted areas and outside, normalized distribution are presented in this study. Normalized version (shown on bottom right) allow easy comparison of shapes.
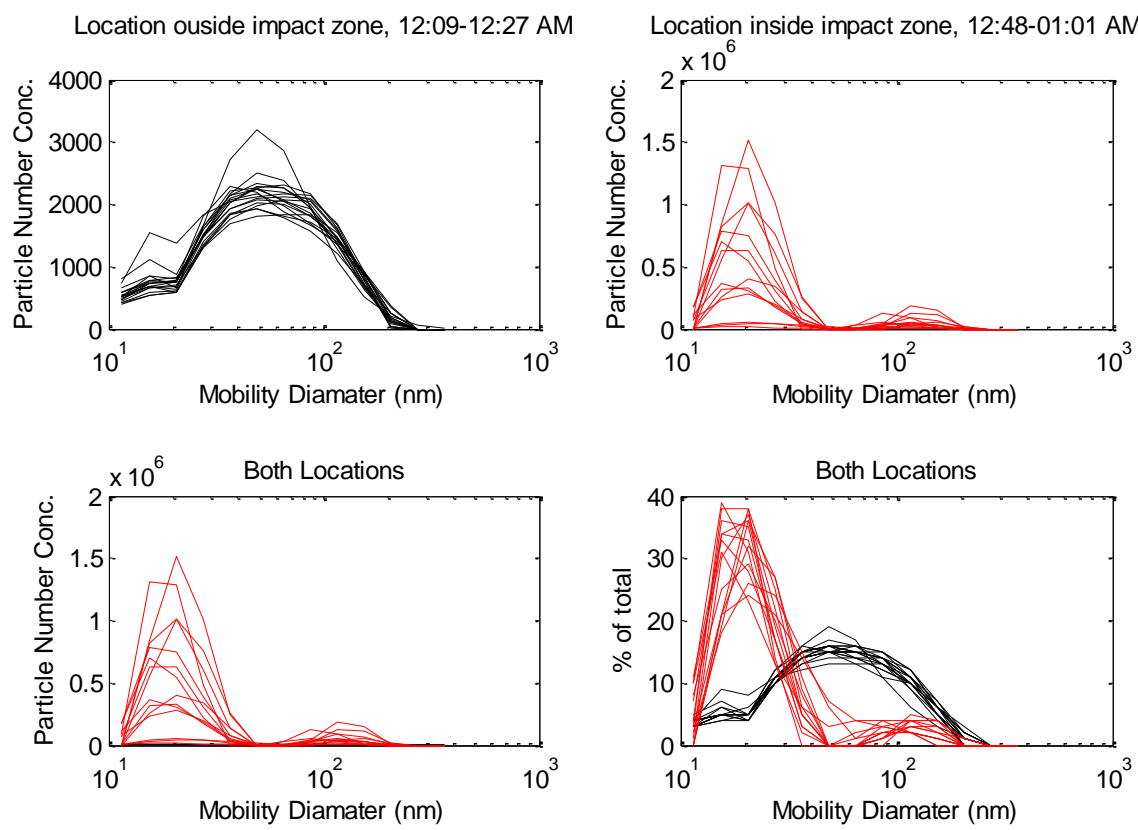

Figure S7: Typical size distributions for measurements conducted inside and outside the impacted areas. 
TDFN values for three additional summer runs are plotted along with the spatial patterns for average size measured using DiSCMini in the following Figure S8.

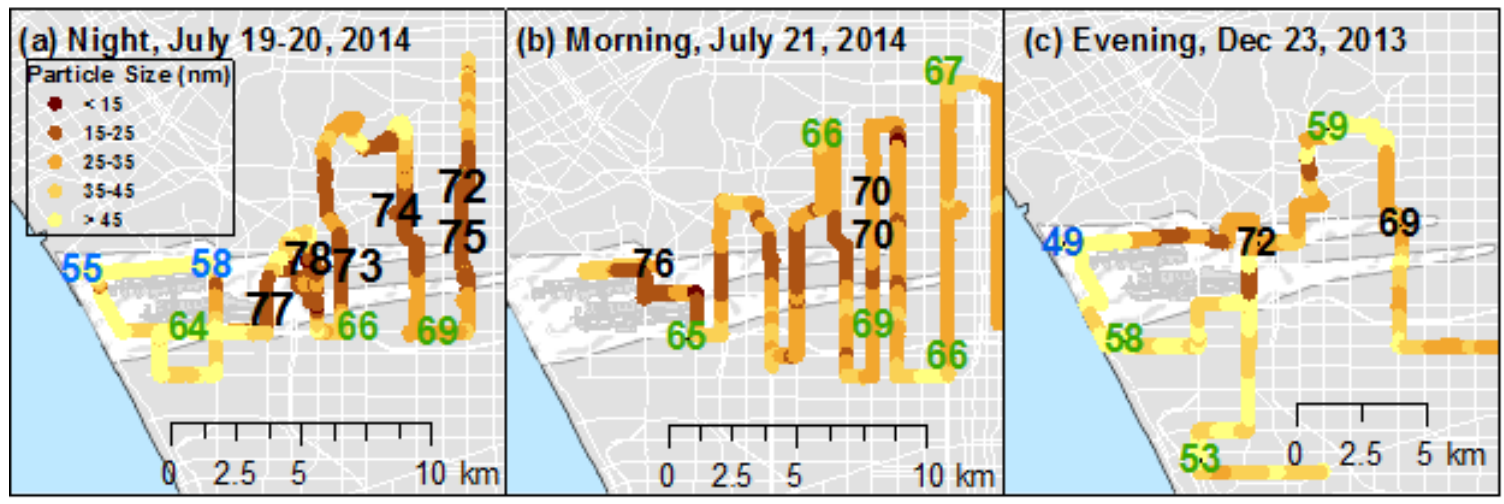

Figure S8: Particle size spatial pattern and TDFN values for stationary monitoring.

\section{REFERENCES}

1. Fierz, M., Houle, C., Steigmeier, P., \& Burtscher, H. Design, calibration, and field performance of a miniature diffusion size classifier. Aerosol Science and Technology, 2011, 45(1), 1-10.

2. Meier, R., Clark, K., \& Riediker, M. Comparative testing of a miniature diffusion size classifier to assess airborne ultrafine particles under field conditions. Aerosol Science and Technology, 2013, 47(1), 22-28.

3. Asbach, C., Kaminski, H., Von Barany, D., Kuhlbusch, T. A., Monz, C., Dziurowitz, N., ... \& Dahmann, D. Comparability of Portable Nanoparticle Exposure Monitors. Annals of Occupational Hygiene, 2012, 56(5), 606-621.

4. Bau, S., Zimmermann, B., Payet, R., \& Witschger, O. A laboratory study of the performance of the handheld diffusion size classifier (DiSCmini) for various aerosols in the 15-400 nm range. Environmental Science: Processes \& Impacts, 2015, 17(2), 261269.

5. Mills, J. B., Park, J. H., \& Peters, T. M. Comparison of the DiSCmini aerosol monitor to a handheld condensation particle counter and a scanning mobility particle sizer for submicrometer sodium chloride and metal aerosols. Journal of Occupational and Environmental Hygiene, 2013, 10(5), 250-258.

6. Hudda, N., Gould, T., Hartin, K., Larson, T. V., and Fruin, S. A. Emissions from an international airport increase particle number concentrations 4-fold at $10 \mathrm{~km}$ downwind. Environmental Science and Technology, 2014, 48(12), 6628-6635.

7. Löndahl, J., Massling, A., Swietlicki, E., Bräuner, E. V., Ketzel, M., Pagels, J., and Loft, S. Experimentally determined human respiratory tract deposition of airborne particles at a busy street. Environmental Science and Technology, 2009, 43(13), 46594664. 
8. Rissler, J., Swietlicki, E., Bengtsson, A., Boman, C., Pagels, J., Sandström, T., Blomberg, A. and Löndahl, J. Experimental determination of deposition of diesel exhaust particles in the human respiratory tract. Journal of Aerosol Science, 2012, 48, 18-33.

9. Westerdahl, D., Fruin, S.A., Fine, P.L. and Sioutas, C. The Los Angeles International Airport as a source of ultrafine particles and other pollutants to nearby communities. Atmospheric Environment, 2008, 42(13), 3143-3155. 